\title{
UMAANÁLISE FENOMENOLÓGICA SOBRE A INFLUÊNCIA DA FÉ NO TRATAMENTO E RECUPERAÇÃO DE PACIENTES
}

Renata Maria Cury Rodrigues* Daniel Rodrigues da Silva* Wilson José Alves Pedro**

\section{Resumo:}

A pesquisa traz visões e pontos de vista sobre a questão da fé. A investigação dessa questão se deu em uma instituição de saúde que trata pacientes com doenças infecciosas, onde pudemos analisar a influência da fé no tratamento e recuperação de pacientes hospitalizados e a visão de alguns profissionais de saúde dentro desta mesma Instituição. A abordagem teórico-fenomenológica é a que subsidia o presente estudo.

Palavras-chave: Aspectos Psicossociais, Fé, Saúde-Doença, Hospitalização, Fenomenologia.

\section{Introdução}

Na condição de futuros profissionais da área da Psicologia, diversos aspectos da relação saúde-doença têm se caracterizado como objeto de preocupação e estudo ao longo da formação, em especial, se considerarmos que a maioria das práticas da psicologia estão hoje contextualizadas no âmbito da saúde. A complexidade deste campo é indescritível, entretanto, identificar e construir um tema, objeto de trabalho para fins de conclusão de curso foi muito desafiante. Nesta perspectiva trilhou-se e optou-se trabalhar uma temática complexa, sem a pretensão de esgotá-la, mas inserila na agenda "psi". Trata-se do fenômeno da fé.

Do ponto de vista filosófico, segundo Durozoi e Roussel (1993,p.186) a fé é "vulgarmente sinônimo de garantia, de segurança válida, ou de fidelidade a um

\section{* Graduados em Psicologia pelo Centro Universitário de Araraquara - Uniara.}

** Doutor em Psicologia Social (PUCSP). Professor Adjunto da UFSCar - Curso de Gerontologia. Docente do PPG Ciência Tecnologia e Sociedade - UFSCar e Docente Colaborador PPG Mestrado Profissional em Engenharia da Produção Uniara. Ex-Professor da Uniara/Unaerp. E-mail: wilsonpedro@ufscar.br. 
compromisso (a "fé jurada"), a noção às vezes encontra-se por exemplo nas expressões boa fé, duplicidade, ou em Sartre, a atitude da consciência, que mascarando-se a verdade, mente a si mesma. (...) A fé designa então uma crença firme, uma certeza que não se baseia em provas racionais. Assim é a fé religiosa, adesão aos dogmas que são considerados verdades reveladas".

E da perspectiva psicossocial, o que se sabe sobre o fenômeno da fé? Ela influencia no processo de recuperação da saúde e enfrentamento das condições adversas da vida humana? E no tratamento e recuperação de pacientes hospitalizados? É possível trabalhar esta "variável"? Por que este fenômeno é tão pouco explorado no decurso da formação profissional e na maioria das vezes no próprio campo científico? Neste sentido, pelas lacunas existentes e pelo fato de existir interesse em refletir e pesquisar sobre as percepções e influências da fé na vida de pessoas em processo de hospitalização, bem como o conhecimento e percepção dos profissionais de saúde sobre este fenômeno, o presente estudo foi construído.

Através da perspectiva teórico-metodológica da fenomenologia (MERLEAUPONTY, 1976; ANGERAMI, 2003; VALLE, 2004) optou-se compreender algumas das possíveis implicações da fé atrelada ao contexto da saúde-doença em processo de hospitalização, visando identificar as possíveis relações em sua manifestação pelos pacientes, analisando a visão singular de cada um acerca das possíveis influências da fé em seu tratamento e recuperação. Agrega-se ainda aos objetivos do estudo compreender a visão dos profissionais da área de saúde em relação a temática fé, para identificar a maneira como lidam com a questão no ambiente hospitalar.

A escolha da abordagem fenomenológica se deu por esta propor caminhos para se chegar a compreensão, visando respeitar a complexidade do real e encontrar o sentido dentro do próprio fenômeno (AUGRAS, 1981). Esta abordagem sintonizase com o termo fé na apreensão/compreensão daquilo que dá à pessoa o sentido último de viver. Pode-se dizer que cada um tem uma fé, independente de ser ou não de natureza religiosa, isto é, independentemente de ela se referir a uma dimensão transcendente, absoluta ou divina (AMATUZZI, 2001).

O presente artigo estrutura-se apresentando à priori, aspectos teóricos sobre a fé, bem como o percurso metodológico percorrido pelos pesquisadores, observandose a seguir as incursões realizadas pela subjetividade-objetividade dos participantes, apresentando a seguir alguns dos aspectos apreendidos com o estudo. Sem a pretensão de esgotar o assunto, nosso desejo maior é que pesquisadores, profissionais, pacientes, familiares, bem como os demais envolvidos, possam sensibilizar-se com a presente reflexão, que fiel aos princípios científico-técnicoéticos de um trabalho acadêmico, possamos avançar cautelosamente às dimensões manifestas dos fenômenos psicossociais que carecem de atenção e preocupação, das diversas ciências e práticas profissionais, e da Psicologia em especial.

\section{Aspectos teóricos}

De acordo com a revisão bibliográfica realizada, constata-se que a conceituação do termo fé está atrelada a diferentes significados. Amatuzzi (1999 apud VALLE, 2004, p.29) diz que o termo fé é definido nos dicionários como crença religiosa, crédito, confiança, virtude teologal. No sentido moderno, fé está associada à Deus e/ou ao sobrenatural, opondo-se ao que é natural e acessível à razão. O autor descreve a fé como um traço de caráter que se mostra como firmeza, determinação, confiança. Ela se torna religiosa quando o seu objeto último é concebido como transcendente e misterioso, a partir da experiência vivida e, posteriormente simbolizada, da relação com o todo. Pode-se dizer que cada um tem uma fé. Independente da natureza desta, religiosa ou não, isto é, independentemente de ela se referir a uma dimensão transcendente, absoluta ou divina. É a confiança básica, aquilo pelo que se vive (AMATUZZI, 2001).

Em termos estritamente filosóficos, pode-se encontrar dois tipos de fé: a perceptiva e a dogmática. Para Angerami (2003), fé perceptiva é aquela situação em que se acredita nas próprias percepções. Para ele fé é a convicção da existência de algum fato ou veracidade de alguma asserção. Acredita-se na audição, visão, olfato, tato e paladar. Acredita-se ver, ouvir e sentir; mas de maneira bastante frágil, os indivíduos dependem de estimulações exteriores que confirmem a própria crença (MERLEAU-PONTY, 1976). A fé perceptiva insere-se na existência humana como se não dependesse de provas ou de confirmação para configurarse como real. Uma fé que para sustentar-se precisa crer em sua própria estruturação. (ANGERAMI, 2003).

De acordo com Angerami (2003), dogma é o fundamento de qualquer sistema ou doutrina. A fé dogmática é estruturada em algo que não depende de fatos para se tornar realidade. Assim, alguém que acredita em Deus não precisa de nada além da sua própria fé para acreditar, nem da fé perceptiva-olhar, audição, tato, etc. O autor afirma a importância de ressaltar que quando se fala em fé dogmática, a impressão primeira é que esta refere-se a aspectos de dogmas religiosos que implicam na crença de determinadas doutrinas místicas e/ou religiosas. Entretanto, a fé dogmática possui um aspecto mais amplo em seu dimensionamento e abarca a fé inquebrantável tanto em algumas doutrinas filosóficas como também em alguns corpos teóricos. Dessa maneira, remete para um imbricamento que direciona o homem a simplesmente afirmar que toda e qualquer teoria depende da fé dogmática.

Com Lukoff(1992 apud FARIA; SEIDL, 2005, p.381) uma importante distinção faz-se necessária: religiosidade de espiritualidade. Define a primeira como adesão a 
crenças e práticas relativas a uma igreja ou instituição religiosa organizada, e a segunda como a relação estabelecida por uma pessoa com um ser ou força superior na qual ela acredita.

De acordo com Spilka e McIntosh (1996 apud FARIA; SEIDL, 2005, p.381), a conceituação de religiosidade inclui aspectos individuais e institucionais, enquanto espiritualidade é um fenômeno apenas individual, identificado com aspectos como transcendência pessoal, sensibilidade "extraconsciente" e fonte de sentidos para eventos na vida.

Torna-se importante, desta forma, distinguir, e não separar, religião de espiritualidade, visando a busca de maior clareza e entendimento sobre a questão.

Para Boff (2006) as religiões são edifícios culturais grandiosos. Elaboram doutrinas e apontam caminhos para a luz. Mas as religiões não anunciam só prédicas, elas acentuam também práticas. As religiões são fonte de ética, isto é, de comportamentos.

Espiritualidade é aquilo que produz dentro dos indivíduos uma mudança interior capaz de dar um novo sentido à vida ou de abrir novos campos de experiência e de profundidade (BOFF, 2006).

\section{Religiosidade e enfrentamento no processo saúde-doença}

Pargament e cols. (1988 apud FARIA; SEIDL, 2005, p.383) argumentam que a religião pode assumir funções diferentes nos diversos estilos de solução de problemas que variam conforme a atribuição de lócus e responsabilidade e do nível de participação da pessoa na resolução do problema. O primeiro estilo é denominado autodirigido (self-directing) em que a responsabilidade pela resolução dos problemas é atribuída ao indivíduo e Deus é concebido como dando liberdade à pessoa para conduzir sua própria vida. O segundo é o delegante (deferring), quando o indivíduo transfere tal responsabilidade a Deus, esperando que soluções venham por meio dos esforços Dele. O terceiro é o chamado estilo colaborativo (collaborative) no qual a responsabilidade é atribuída tanto ao indivíduo como a Deus, ambos percebidos como participantes ativos na solução de problemas.

Pargament (1997 apud FARIA; SEIDL, 2005, p.383) defende que as pessoas lidam com os problemas da forma que é possível em determinado momento, pois as opções de enfrentamento são limitadas pela pressão dos eventos, pelo sistema de crenças predominante e pelas avaliações dos recursos disponíveis para enfrentá-los.

A aplicação desses conceitos no campo de saúde sugere que crenças religiosas podem favorecer a esquiva ou atrasar a busca de cuidados médicos ou modalidades de tratamento, no caso em que o paciente designa todo o controle de sua doença a Deus (CHATTERS, 2000).
Sobre o processo de hospitalização e a visão sobre postura de profissionais de saúde acerca da "assistência espiritual"

Analisar a condição do indivíduo que passa pelo processo de hospitalização, o modo como "olha" o seu próprio ser, a configuração da doença em sua vida, as possíveis conseqüências, mudanças na rotina, e nas crenças dos mesmos durante esse processo é de fundamental importância para a referente pesquisa, já que boa parte dela se deu dentro do ambiente hospitalar.

Segundo Angerami (2003), a hospitalização é agravada muito mais por conceituações apriorísticas do que propriamente por si mesma. Muito mais do que buscar na patologia que determinou a hospitalização, a decorrência do sofrimento vivido pelo paciente, a direção da análise refere-se aos fatores subjetivos que estão determinando a própria conceituação de enfermidade e, por assim dizer, do nível desse sofrimento.

A doença adquire a condição de fato pela maneira como é apreendida pela consciência; é na consciência que determinados diagnósticos ganham significados de irreversibilidade de sua transformação em aspectos que envolvem até mesmo a cura (SARTRE, 1981).

De acordo Angerami (2003), no entanto, o paciente que sofre, padece em níveis orgânicos com manifestações de desconforto que o simples processo de conscientização de sua origem não tem o poder de promover alívio. Negar a dor do outro é negar a sua própria realidade.

De acordo com Frankl, (1992 apud VALLE, 2004, p.29-30) a religião e a fé proporcionam ao homem um estado de segurança e sustentação espiritual ímpar, contribuindo para a conservação de seu equilíbrio vital. Ter fé em algo pode ser encontrar um sentido de vida. O ser humano está sempre orientado para o futuro, para algo que o transcenda, seja um projeto a realizar, uma pessoa a encontrar. A transcendência de si mesmo constitui a essência da existência humana e o que impulsiona o homem é a vontade de sentido.

Para Daniel (1983), quando os aspectos espirituais são levados em conta nos cuidados ao paciente e aos seus familiares, os resultados podem ser notados. Traduz-se pela confiança manifestada pelas pessoas ao receberem um tipo de ajuda. É preciso ser sensível ao outro, apreender suas necessidades, enfim, sercom-o-outro, cuidar dele, permitir a ele ser ele mesmo nesse processo em que o ser-com possibilita a sua compreensão de ser-si mesmo que leva a compreensão do outro. Assim, o outro é de imediato desvelado na solicitude cuidadosa.

De acordo com Valle (2004), o profissional de saúde deve evitar destruir a esperança com um discurso brutal. É importante manter a confiança de quem 
está sendo cuidado, ajudá-lo e apoiá-lo nos momentos em que ele tiver dificuldades.

Para Michelazzo (2002 apud VALLE, 2004, p.37), quando o outro necessita de ajuda profissional, a postura proposta deve ser a da busca de algo que ele já possui de certa maneira: o outro já tem uma compreensão implícita, pré-ontológica do sentido de sua dor, da sua dificuldade, do seu sofrimento e, até mesmo, das suas possibilidades negadas. Nos encontros com o paciente e com a família cabe ao profissional acompanhar e ajudar a ampliar aquilo que o outro sabe préontologicamente, favorecendo que se coloque em uma perspectiva ontológica e que se aproxime da sua condição humana mais primordial.

\section{Percurso metodológico}

Inserido no âmbito dos estudos psicossociais, o presente estudo caracteriza-se pelo seu caráter exploratório-descritivo-compreensivo, pautado na abordagem fenomenológica.

Após elaboração do projeto de pesquisa, apresentação e aprovação do Comitê de Ética e Pesquisa do Centro Universitário de Araraquara - Uniara, o projeto foi também apreciado e aprovado pelo Comitê de Ética da Instituição Hospitalar a qual a pesquisa foi realizada.

O trabalho de campo se iniciou com a visitação às instalações da instituição pelos pesquisadores, visando identificar pacientes que estavam aptos a participarem do estudo. Para que essa escolha fosse feita, foram necessárias informações dos profissionais de saúde do local.

O estudo contempla dois grupos distintos: pacientes hospitalizados e profissionais da saúde. No primeiro grupo foram entrevistados seis pacientes em período de internação e no segundo grupo foram entrevistados seis profissionais da área de saúde que trabalham no mesmo local, sendo estes dois enfermeiros, dois auxiliares de enfermagem, um médico e um psicólogo. Todos os participantes do estudo possuem idade entre 25 e 45 anos.

A escolha dos profissionais de saúde se deu mediante a indicação da Direção da divisão de saúde da instituição, priorizando a participação de profissionais que tem maior proximidade com os pacientes, podendo fornecer informações mais substanciais sobre a temática a ser questionada.

A pesquisa previu a realização de dois encontros, com os sujeitos entrevistados, nas próprias dependências do hospital.

No primeiro encontro foi realizada uma apresentação pelos pesquisadores sobre a temática e os objetivos da pesquisa, bem como o preenchimento do termo de consentimento pré-informado. Constituiu-se, portanto, o rapport.

REVISTA UNIARA, $n .^{0} 21 / 22,2008 / 2009$
No segundo encontro, foram coletados os dados através de uma entrevista semi-estruturada. Toda a entrevista foi gravada em áudio e posterior transcrita integralmente para fins de análise. Ambos encontros tiveram duração de aproximadamente uma hora.

Durante todo o processo os procedimentos éticos com seres humanos foram observados.

De acordo com os pressupostos teórico-metodológicos de abordagem fenomenológica, os dados foram analisados através de eixos temáticos subdivididos em: conhecimento acerca da doença e reação ao descobri-la, fatores que auxiliam o tratamento, relação da fé com diversos fatores, religião e alteração da fé do paciente após a descoberta da doença, referindo-se estes aos pacientes; e eixos temáticos sub-divididos em: fé inserida no contexto hospitalar, estudos e pesquisas sobre a fé inserida no contexto hospitalar, incentivo à fé do paciente e fé como alternativa paralela no auxílio ao tratamento e à uma possível cura, referindo-se aos profissionais de saúde. A análise foi qualitativa, comparando as narrativas e questões teóricas com uma proposta compreensiva.

\section{Sobre os resultados e discussão}

Os resultados e discussão serão apresentados primeiramente na perspectiva dos pacientes e a seguir a perspectiva dos profissionais conforme as categorias temáticas analisadas. Quanto aos pacientes observa-se o conhecimento acerca da doença e a reação ao descobri-la; fatores que auxiliam o tratamento; relações da fé com os fatores e alterações da fé no processo de tratamento. Quanto aos profissionais da saúde a análise compreensiva contempla: a fé inserida no contexto hospitalar; estudos e pesquisas sobre o fenômeno da fé; práticas informais recorrentes e alternativas.

\begin{tabular}{|l|l|l|l|l|l|}
\hline \multicolumn{1}{|c|}{$\begin{array}{c}\text { Sujeitos } \\
\text { Entrevistados }\end{array}$} & \multicolumn{1}{|c|}{ Sexo } & \multicolumn{1}{|c|}{ Idade } & \multicolumn{1}{|c|}{ Patologia } & $\begin{array}{c}\text { Tempo de } \\
\text { internação }\end{array}$ & Religião \\
\hline Sujeito 1 & Feminino & 29 anos & $\begin{array}{l}\text { Tuberculose Multi } \\
\text { Resistente }\end{array}$ & $\begin{array}{l}1 \text { ano e } 8 \\
\text { meses }\end{array}$ & Católica \\
\hline Sujeito 2 & Masculino & 52 anos & $\begin{array}{l}\text { Tuberculose Multi } \\
\text { Resistente }\end{array}$ & 1 ano & Católica \\
\hline Sujeito 3 & Masculino & 33 anos & Tuberculose & 2 meses & Católica \\
\hline Sujeito 4 & Masculino & 32 anos & Tuberculose & 2 meses & Evangélica \\
\hline Sujeito 5 & Masculino & 35 anos & HIV & $\begin{array}{l}1 \text { mês e } \\
\text { quinze dias }\end{array}$ & Espírita \\
\hline Sujeito 6 & Masculino & 45 anos & HIV & 3 dias & Espírita \\
\hline
\end{tabular}

Quadro 1. Pacientes participantes do estudo. 


\begin{tabular}{|l|c|c|c|c|}
\hline $\begin{array}{c}\text { Sujeitos } \\
\text { Entrevistados }\end{array}$ & Sexo & Idade & $\begin{array}{c}\text { Cargo Desempenhado } \\
\text { na Instituição }\end{array}$ & $\begin{array}{c}\text { Tempo que trabalha } \\
\text { na Instituição }\end{array}$ \\
\hline Sujeito 1 & Feminino & 47 anos & Psicóloga & 2 anos \\
\hline Sujeito 2 & Masculino & 46 anos & Médico & 15 anos \\
\hline Sujeito 3 & Feminino & 45 anos & Enfermeira & 7 anos \\
\hline Sujeito 4 & Feminino & 51 anos & Enfermeira & 14 anos \\
\hline Sujeito 5 & Feminino & 56 anos & $\begin{array}{c}\text { Auxiliar de } \\
\text { Enfermagem }\end{array}$ & 23 anos \\
\hline Sujeito 6 & Masculino & 41 anos & $\begin{array}{c}\text { Auxiliar de } \\
\text { Enfermagem }\end{array}$ & 9 anos \\
\hline
\end{tabular}

Quadro 2. Profissionais participantes do estudo

Compreendendo visões dos pacientes hospitalizados sobre o fenômeno em estudo. Conhecimento acerca da doença e reação ao descobri-la

De acordo com as entrevistas realizadas percebe-se que a maioria dos participantes não tem conhecimento acerca de sua patologia. Os sujeitos Pacs. 1, 2, 3 e 4 expressam que não sabiam o que significava sua doença. $O$ sujeito 5 relata apenas: "Ah meu conhecimento é que o HIV é uma doença que não mata ninguém. Hoje tem medicação". Apenas o sujeito 6 diz sobre algumas maneiras de se contrair e agravar a doença: "Eu sei que é uma doença que antigamente matava, não tinha essas tecnologias de hoje. Mas eu sei que é uma doença transmissível sexualmente, através de seringa, relação anal, essas coisas. É uma doença oportunista, se você não toma a medicação, aí a resistência abaixa e pega doenças".

A reação, após a confirmação do estabelecimento da patologia é sempre variada. Alguns negam a doença, buscam formas de fugir da situação, outros entram em estado depressivo e outros ainda a associam com a morte como mostram os relatos dos pacientes 1, 5 e 6: "Eu não acreditei nela. Eu comecei a beber. Mas agora tô fazendo o tratamento certinho" (Sujeito 1). "No começo eu entrei em depressão, pensei que ia morrer, mas depois você percebe que tem jeito" (Sujeito 5). "Eu falei, vixi, tô morto. Fiquei daquele jeito, agora me acostumei né". (Sujeito 6).

Os sujeitos 2, 3 e 4 apresentam reações mais amenas. O primeiro diz: "A minha reação foi "meio chateado", me abalou um pouco". O segundo não esboça o tipo de reação emocional que teve e o último relata: "Reagi normal, eu já tenho o vírus do HIV, para mim é só mais uma doença". Dessa forma, o que torna a experiência estressante não é a situação em si, mas o olhar e a maneira como o paciente enfrenta a mesma.

\section{Fatores que auxiliam o tratamento}

A maioria dos sujeitos declararam que acreditam tanto nos medicamentos quanto na força de Deus, para a recuperação e até mesmo a cura de suas doenças. De acordo com eles a fé pode auxiliar no tratamento. Este fato pode ser melhor observado através das narrativas apresentadas dos próprios sujeitos. "O que pode me ajudá, é só eu crer em Deus mesmo. Pode ser os medicamentos que podem ajudar também" (Sujeito 1). "Ahhh, eu acredito que os remédio fazem efeito pra mim, ajuda muito, e, eu já tô tomado outros medicamentos, babosa com suco fora do hospital e eu tenho fé em Deus, assim, acho que melhoro 100\%. Saindo daqui vou buscar uma religião" (Sujeito 2). "Acredito no tratamento e na cura divina que é Deus. Fora isso, mais nada" (Sujeito 4). "Esse coquetel tá sendo muito bom. Mas se saísse uma medicação pra melhorar, pra zerar o vírus, seria melhor. Eu acho também que a fé remove montanhas. Tenho fé em Deus. Pra Ele nada é impossível né? Só que tipo assim uma vez veio um pastor de igreja e falô que eu podia pegar meus coquetéis e jogá tudo fora, e eu falei não. A fé ajuda. Mas eu nunca tentei só me curar pela fé" (Sujeito 5). "Deus. Deus pode todas as coisas né e alguma coisa ele deve ter comigo, alguma coisa especial. Porque meu amigo, 20 anos quase, aproximadamente de HIV, tô aqui ainda, sei lá, é Deus. E vou continuar o tratamento também né?" (Sujeito 6).

Os sujeitos entrevistados relacionam-se com o modelo de enfrentamento chamado estilo colaborativo (collaborite) de Pargament e cols. (1988 apud Faria; Seidl, 2005, p.383) no qual a responsabilidade na solução de problemas é atribuída tanto ao indivíduo como a Deus, ambos percebidos como participantes ativos.

\section{Relação da fé com diversos fatores}

Metade dos sujeitos relaciona a sua fé e o seu desejo de recuperação a outros fatores, que não estão apenas relacionados à religiosidade. O sujeito 1 diz: "O que me ajuda bastante é meus irmãos. Me dá força, eu adoro eles. Acho que é por isso que eu tô viva hoje. Quero ver eles felizes e eu também quero ser feliz". O sujeito 3 relata: "O que eu quero é sai daqui e consegui o que eu perdi, poder ter uma família. Porque primeiro eu não tinha fé, tava no mundo das drogas. Essa fé foi recuperada quando eu vim para cá, com a doença e eu vi que não era nada daquilo que eu pensava". O sujeito 6 diz que acredita no poder que sua mente tem sobre seu corpo: "Tenho fé no poder que minha mente tem sobre meu corpo. Porque se você bota na sua cabeça que você vai morrer sei lá você acaba indo.

Os sujeitos 2, 4 e 5 relacionam a sua fé, respectivamente, na religião; na cura divina e no tratamento; e em Deus, ressaltando o que já haviam dito anteriormente.

Pode-se relacionar os relatos apresentados ao que diz Frankl, (1992 apud Valle, 2004, p.29 -30): ter fé em algo pode ser encontrar um sentido de vida. O ser humano está sempre orientado para o futuro, para algo que o transcenda, seja um projeto a realizar, uma pessoa a encontrar. A transcendência de si mesmo constitui a essência da existência humana, é o que impulsiona o homem, é a vontade de sentido.
Uma análise fenomenológica... 


\section{Alteração da fé do paciente após a descoberta da doença}

Em relação a alteração na fé dos sujeitos após a descoberta da doença percebese a variedade de mudanças tidas por cada um. O sujeito 1 diz: "Sempre acreditei em Deus. Só que depois que eu tive essa doença passei a acreditar mais, a ler a bíblia e crer mais em Deus e em meus irmãos". O sujeito 2 diz: "Mudou com o agravamento da doença. Eu sofri quando eu abandonei o medicamento que eu tomava antes, aí eu perdi a fé na cura, mas como Deus é grande e a gente tem muitos amigos que aconselham a gente, então eu procuro agora ter minha fé sempre em dia com a Igreja Universal". O sujeito 4 diz: "Eu passei a ter mais fé. Deus me mostrou um caminho, e eu consegui, desviei do caminho errado e de tá vivo é mais uma prova de fé né? Que Ele existe e que eu tenho que crer cada vez mais". O sujeito 5 diz: "Eu vô falar que quando eu descobri que eu era portadora, a minha fé eu acho que foi maior. Foi aumentando mais". O sujeito 6 diz: "Eu acredito em Deus, não tem nem jeito de não acreditar. $O$ planeta tem que ter o verdadeiro criador, o dono do reino, da benevolência. E hoje eu passei a acreditar e pensar mais nisso, ter mais fé, se Ele não tivesse um plano especial pra mim, eu não taria vivo depois de tudo que passei".

O sujeito 3 foi o único que não relatou alterações em sua fé: "Minha fé está igual. Não está $100 \%$, está mais ou menos".

Embora cada paciente tenha exposto a alteração percebida de forma diferenciada, constata-se que a maioria deles apresentou alteração em sua fé após o descobrimento ou agravamento da doença, direcionando sua fé predominantemente a alguma religião ou objeto transcendente.

\section{Compreendendo as visões dos profissionais}

\section{Fé inserida no contexto hospitalar}

As visões dos profissionais acerca do tema são expressas de forma diferenciada, mas nenhum relato nega a importância da fé no contexto hospitalar. Os profissionais muitas vezes incentivam o uso da fé, verificando o benefício tido no tratamento e bem estar dos pacientes devido a utilização deste recurso.

De acordo com o sujeito 1, "Independente de religião vejo os pacientes acreditarem em Deus. Muitas vezes vejo eles no altar. Você percebe que sempre um ou outro está ali. O hospital abre espaço para os pacientes exporem sua religião". Já o sujeito 2 diz: "Olha, a gente percebe realmente que os pacientes aqui têm realmente fé, a maioria têm fé que o tratamento vai dar certo e isso acaba contribuído para o êxito do tratamento. Além logicamente que eles têm as religiões deles. A gente aqui, a Instituição, é aberto também para qualquer tipo de religião. Às vezes vem pastor, vem outros tipos de pregação aqui. Mas eu acredito que realmente eles têm fé. A maioria isso é certeza". O sujeito 3: "Acho queé um tema bonito e é importante você ter fé. Sem fé, você fica muito para baixo e acho que contribui para a doença agravar mais". O sujeito 4 diz: "Acho que a fé deve ser respeitada. A instituição deve abrir espaço para todos os tipos de religião, é uma coisa de respeito de um com o outro". De acordo com o sujeito 5: "A gente tem várias experiências né. Nessa instituição é de pacientes bem debilitados, tanto faz da TB (Tuberculose) quanto do HIV (Síndrome da Imunodeficiência Adquirida). Então eu acho que é muito importante ter fé, e, é o que a gente prega muito aqui. Na verdade, a gente tem consciência que a gente ajuda bastante, os pacientes ficam mais motivados a continuarem o tratamento. Dependendo do jeito que você falar da sua fé pra o paciente ele vai acatar, principalmente no momento que ele mais precisar". O sujeito 6 diz apenas que seu conhecimento é amplo devido suas experiências pessoais.

Constata-se que a fé inserida no contexto hospitalar é percebida como positiva pela maioria dos profissionais de saúde, existindo o respeito e/o incentivo por parte dos mesmos.

De acordo com Daniel (1983) quando os aspectos espirituais são levados em conta nos cuidados ao paciente e aos familiares, os resultados podem ser notados. Traduzem-se pela confiança manifestada pelas pessoas ao receberem um tipo de ajuda que pode ser desde uma presença serena, um olhar compassivo, um segurar as mãos, um toque, uma palavra de conforto, de fé e esperança.

Estudos e pesquisas sobre a fé inserida no contexto hospitalar

A maioria dos sujeitos $(2,3,4$ e 5) possuía pouco ou nenhum conhecimento de estudos e pesquisas acerca do assunto. Apenas os sujeitos 1 e 6 mencionaram saber de estudos relacionados ao tema. Como se pode constatar, as informações referentes ao assunto no meio científico, no campo da saúde, ainda são escassas e incompletas.

No entanto, a falta de informações científicas sobre o assunto não impediu que os profissionais incentivassem e/ou respeitassem as dimensões da fé no contexto hospitalar visando auxiliar o tratamento e recuperação dos sujeitos internados no hospital.

\section{Práticas informais recorrentes}

Todos os profissionais de saúde relataram incentivar a fé do paciente no contexto de hospitalização. Dizem orientar e/ou incentivar a fé relacionando-a aos aspectos religiosos ou à espiritualidade. Utilizam-na também visando incentivar os indivíduos internados a continuarem o tratamento, ter esperança e manter a auto-estima. $\mathrm{O}$ sujeito 1 relata: "Informei os pacientes sobre um pastor que estaria vindo aqui uma vez por mês, que ia ter uma reunião sobre espiritualidade, que eu também acho importante incentivar, mesmo que não esteja ligada a uma religião. Muitas vezes eles perguntam, então eu digo que é bom ter uma religião. Ela tem que vir de encontro aos princípios de cada um". 
O sujeito 2 diz: "Já incentivei. Olha a gente às vezes se utiliza desse meio porque a gente percebe que o paciente muitas vezes esgotou já outros tipos de esperança, ou de incentivo. A gente sempre incentiva o paciente a ter esperança de que o tratamento vai dar certo. Mas chega em determinado ponto que o paciente acaba ficando, realmente, desestimulado, principalmente quando o tratamento não vai dando muito certo. Então nesses casos você tem que agir de outra forma, você tem que lançar mão desses meios, pedir para ele ter esperança, ter um pouco de fé né? Que o tratamento vai dar certo realmente. Para ele acreditar na equipe que ele tá trabalhando né, acreditar nele mesmo, que ele tem condições de superar a doença. Dessa forma, percebe-se que muitos pacientes começam a se motivar". O sujeito 3 relata: "Eu sempre incentivo o paciente a ter fé. Fé em Deus. Rezar. Não perder a esperança". O sujeito 4 diz: "O importante é a pessoa acreditar naquilo que ela está buscando. Quando você pega aqueles que são bem ateus, você pode de alguma forma orientá-los a procurar uma religião porque assim as coisas às vezes saem de maneira mais fácil. A finalidade é para ela buscar alguma coisa, para ela conseguir atingir seu objetivo, não necessariamente uma religião". O sujeito 5 conta sobre uma experiência tida: "Teve um caso de um paciente também, que ele era assim, bastante resistente às drogas. Comecei a falar para ele de Deus, da fé. Dizia que a gente tem que ter um Deus, ele foi ouvindo e daí em 4 meses ele saiu de alta. Então isso prova que a fé existe e pode mudar muita coisa e pode contribuir, principalmente nos tratamentos".

Por fim, o sujeito 6 diz: "Incentivei com a finalidade de ajudar o paciente a se recuperar, usando a fé como um fundamento para a melhoria da auto-estima. Na fé religiosa, na fé medicamentosa, e na fé nele mesmo. Então os três aspectos são importantes. Então a fé de um ponto de vista geral, a fé religiosa, que para mim é fundamental na constituição do ser humano, a fé no tratamento, e a fé em si próprio para que ele seja re-inserido na sociedade são fatores importantíssimos na recuperação total do paciente. No dia a dia nós estamos vendo os resultados dessa ajuda que a gente tem dado a eles pra encarar a fé como sendo fundamental na recuperação de sua vida".

No entanto, além do incentivo dado pelos profissionais para que os pacientes tenham uma religião, existe também o incentivo para que acreditem em algo que lhes traga satisfação, não fazendo referência apenas a religiosidade em si, embora considerem que seja um dos caminhos.

Fé como uma alternativa paralela no auxílio ao tratamento e a uma possível cura

De acordo com o relato apresentado pela maioria dos profissionais de saúde, os pacientes utilizam-se da fé visando auxiliar o tratamento e/ou buscando uma possível cura. Apenas os sujeitos 3 e 4 dizem não ter conhecimento sobre a utilização da fé

REVISTA UNIARA, $n .^{0} 21 / 22,2008 / 2009$ pelos pacientes. O sujeito 1 relata: "Eu acho que eu nunca atendi um paciente aqui no hospital que não acreditasse em nada. Eu percebo que eles acreditam, que eles tem fé e isso ajuda no tratamento deles". O sujeito 2 diz: "Eu acho que a fé pode auxiliar o tratamento. De forma paralela pode ser que sim. Não como única forma para um resultado positivo do tratamento. Eles têm fé no tratamento, em Deus mesmo, na religião deles. A maioria tem realmente fé em Deus, e eles que Deus é que vai curar ele, a gente percebe mesmo". O sujeito 5 diz: "Lógico. Claro que auxilia. A gente vê a importância disso pra eles, você vê a diferença, no tratamento deles, no comportamento deles quando começam a ter fé novamente". Por fim, o sujeito $6 \mathrm{diz}$ "Já aconteceram vários casos assim, em que a fé auxiliou o paciente que estava internado. Não foram nem um, nem dois, nem três casos. Foram vários. Os pacientes têm fé em diversas coisas, no tratamento, na medicação, alguns acabam encarando isso realmente como algo necessário a suas vidas. E crêem nesse tratamento. Outros pendem para a fé religiosa. Os pacientes freqüentemente têm sua fé em Deus e isso os ajuda a se recuperar. Então a fé, ela não é uma exclusividade de uma religião. Existe a fé natural, essa que nós estamos falando, na medicação, no tratamento, na recuperação, e a fé espiritual que transcende ao natural né. As duas, elas são importantes na recuperação do indivíduo. Se vocês fizerem uma pesquisa aqui dentro do hospital vocês irão ver que existe muitos casos de reincidência da doença, mas vocês vão ver que aqueles que se utilizaram da fé e que permaneceram usando essa fé lá fora, eles não retornam. Você pode ficar curado só com as drogas, mas aí você vai voltar, a sua alma, os seus sentimentos, suas emoções, sua razão, seu psique, não foi tratado por esse elemento tão importante que é a fé".

Através dos relatos nota-se que a fé é vista pelos profissionais como uma estratégia de enfrentamento que auxilia o tratamento e recuperação dos pacientes. Nenhum profissional fez referência a fé relacionada apenas à religião.

De acordo com Amatuzzi (2001) a fé se torna religiosa quando passa a ter um objeto transcendente, um pólo objetivo absoluto incondicionado, afirmado implicitamente no interior do próprio dinamismo de confiança que a constituiu.

\section{Considerações finais}

Percebeu-se através da pesquisa que o processo de hospitalização trouxe diversas mudanças na vida dos sujeitos entrevistados.

A família é citada como sendo um dos incentivos para os pacientes buscarem a melhora e/ou cura de sua doença e para a saída do hospital. Muitos têm sonhos relacionados à re(construção) de uma família. Existe um ideal externo a ser buscado e uma mobilização interna dos pacientes para que ele seja atingido.

A fé tida no tratamento e na equipe de saúde foi outro fator citado constantemente 
pelos pacientes que visam buscar a cura através dos métodos tradicionais tidos pela medicina e tecnologia. Não houve nenhum caso em que o paciente negasse os efeitos positivos da medicação e do tratamento que está sendo submetido.

O poder que a mente tem sobre o corpo foi citado como sendo um fator que auxilia na recuperação e possível cura. De acordo com os pacientes que acreditam nessa ligação, os "pensamentos positivos" são tidos como uma das razões para estarem vivos.

A fé religiosa ou relacionada a um objeto transcendente aparece no discurso de todos os pacientes. Associam a cura de suas patologias também a Deus.

"Deus" é a configuração religiosa que aparece absolutamente com maior frequiência nas falas dos sujeitos entrevistados quando fazem referência à cura de sua doença.

A fé, associada a alguma religião ou figura religiosa, é vista pelos pacientes como um dos fatores cruciais para a recuperação de seu estado de saúde. Em nenhum dos casos aparece como sendo a única forma procurada para que ocorra a reabilitação e até mesmo a cura da doença.

Em relação aos profissionais de saúde do local, percebe-se primeiramente o interesse despertado neles pelo tema da pesquisa. Amaioria dos entrevistados relatou a necessidade de pesquisas abordando questões referentes à fé e à religião, já que percebem como esta temática permeia o ambiente hospitalar.

Todos os profissionais entrevistados relataram que a féé algo fundamental para o tratamento e recuperação dos pacientes. Não é apenas a fé religiosa que é incentivada, a maioria dos profissionais relatou incentivar os pacientes a acreditarem no tratamento ao qual estão sendo submetidos, expondo os benefícios e as conseqüências de sua utilização.

Dessa forma, o paciente se torna consciente da sua condição de saúde, evitando conceituações apriorísticas que podem causar sofrimento e ansiedade.

Os profissionais de saúde entrevistados mostraram-se sensíveis ao processo de adoecimento e buscam auxiliar os sujeitos internados em suas necessidades físicas e emocionais, mostrando que o respeito das condições de saúde, no seu conceito mais amplo, dos pacientes, não é deixado de lado.

\section{Referências bibliográficas:}

AMATUZZI, M.M. Esboço de teoria do desenvolvimento religioso. Entre necessidade e desejo: diálogos da psicologia com a religião. São Paulo: Edições Loyola, 2001.

ANGEL, H.F.; KRAUSS, A. O Deus interdisciplinar. Viver: mente \& cérebro.
São Paulo, v.13, n.147, p.48-53, 2005.

ANGERAMI, V.A. Temas existenciais em psicoterapia. São Paulo: Pioneira Thomson Learning, 2003.

AUGRAS, M. O ser da compreensão. Petrópolis: Vozes, 1981.

BOFF, L. Espiritualidade: um caminho de transformação. Rio de Janeiro: Sextante, 2006.

CHATTERS, L. Religion and health: public health research and practice. Annual Review of Public Health. Michigan, v.21, p. 335-367, 2000.

DANIEL, L.F. Atitudes interpesoais em enfermagem. São Paulo: EPU, 1983

DUROZOI, G; ROUSSEL, A. Dicionário de filosofia. Campinas: Papirus, 1993.

FARIA, J.B; SEIDL, E.M.F. Religiosidade e enfrentamento em contextos de saúde e doença: revisão da literatura. Psicologia: reflexão e crítica. Brasília, v.18, n.3, p.381-389, 2005.

MERLEAU-PONTY, M. O visível e o invisível. São Paulo: Perspectiva, 1976.

SARTRE, J.P. El ser y la nada. Buenos Aires: Editorial Losada, 1981.

VALLE, E.R.M. Psico-oncologia pediátrica: fé e esperança como recursos existenciais. In:___ Vanguarda em psicoterapia fenomenológico existencial. São Paulo: Pioneira, 2004. p.27-40.

\section{Title:}

\section{A PHENOMENOLOGICAL ANALYSIS ON THE INFLUENCE OF} FAITH IN PATIENTS' TREATMENT AND RECOVERY.

\section{Abstract:}

The research brings visions and points of view on the issue of faith. The investigation of this question has taken place in a health institution that treats patients with infectious diseases, where we could examine the influence of faith 
in the treatment and recovery of inpatients and the view of some health care professionals within the same institution. The theoretical and phenomenological approach has been adopted in the present study.

Keywords: Psychosocial Aspect, Faith, Health-illness, Hospitalization, Phenomenology. 